\title{
Research on Modern Enterprise Management Accounting Development Trend and the Influences on Promoting the Enterprise
}

\author{
Dongliang Pan \\ Hebei Polytechnic Institute, \\ Shijiazhuang,Hebei,050091 China
}

\author{
Jingjing Cao \\ Hebei Polytechnic Institute, \\ Shijiazhuang,Hebei,050091 China
}

\begin{abstract}
In this paper, we conduct basic research on the modern enterprise management accounting development trend and the influences on promoting the enterprise. Management accounting subject refers to the management accounting as the services of a particular unit. Because of the management accounting mainly provides the useful decision information to the internal management of internal accounting need not follow generally accepted accounting standards, thus main body of management accounting can is administrative. Depending on the enterprise internal management needs, the subject of the management accounting can be throughout the enterprise, also can be unit of enterprise interior various levels of responsibility. Management accounting mainly through a series of special methods using financial accounting information and other relevant data sorting, calculation, comparison and analysis, which can make the enterprise management personnel at all levels of all economic activity in the daily planning and control, and to help business leaders to make the whole set of the information processing system of decisions. Our research conducts detailed and in-depth analysis on the related issues that serves as the novel paradigm.
\end{abstract}

Keywords- Management Accounting, Development Trend, Modern Enterprise, Promoting.

\section{Introduction}

Financial accounting is the enterprise formed on the basis of the traditional accounting, regulated by generally accepted accounting principles, to provide a general financial reporting in basic corporate external stakeholders as the main goal of the accounting system. Accounting development cannot leave the development of economy, the same is true of financial accounting as a branch of accounting, along with our country economy rapid development, capital markets are further improved, entered the era of information technology in our country, the development of the financial accounting are put forward higher request, therefore predict financial accounting will develop faster in the future [1-2].

Modern enterprise only continuously for enterprises to carry out strategic adjustment, strengthen the enterprise internal management and system construction, in order to better adapt to the needs of economic development, and through the implementation of the accounting management strategy can help enterprises to make more scientific and reasonable technical innovation strategy and marketing strategy to promote the development of enterprises. Companies want to be in an impregnable position in the fierce market competition, must according to the change of market economy on the accounting strategic adjustment. It is in fact the basic accounting strategy and enterprise financial management strategy, it as relations with the enterprise financial activities and financial management strategy and important decisions that is the core of the enterprise strategy.

Since the 1980s, the enterprise life cycle theory is popular all over the world. In fact enterprise is also and all kinds of living things that is a development process from birth to death, companies like general abstraction of organic life. Enterprise life cycle theory popular in all over the world is full of tells us that when the enterprise in 
different stage of development, the enterprise in the competition in the market risk is not the same size, and thus make enterprise's financial position is also in constant change. Therefore, for the enterprise's financial position can't keep constant, the enterprise's financial strategic target and the choice are according to primary enterprise life cycle forms, and formulate the corresponding methods. Enterprise development is the enterprise after a difficult and the risky startup stage after stage. When enterprises enter the development, for core demand of the market gradually expanded, the improved products, enterprise internal system of various specifications of system was basically completed, in the society of the corporate image is being established, progresses day by day and the overall condition of the enterprise is full of youthful spirit is this stage [3].

Management accounting is an emerging science the study of it in our accountant forum has not yet formed a complete set strict basic theory system and method of use system, the lack of practicability, maneuverability and the functional studies. Basic management accounting tools are imported from abroad, the domestic most companies cannot very good grasp of the use of management accounting tools, there are quite a number of enterprise managers don't agree with management accounting tools, to ask for the kind of management accounting tools, therefore, application of management accounting tools in an enterprise has been greatly hindered. The figure one shows the principles.

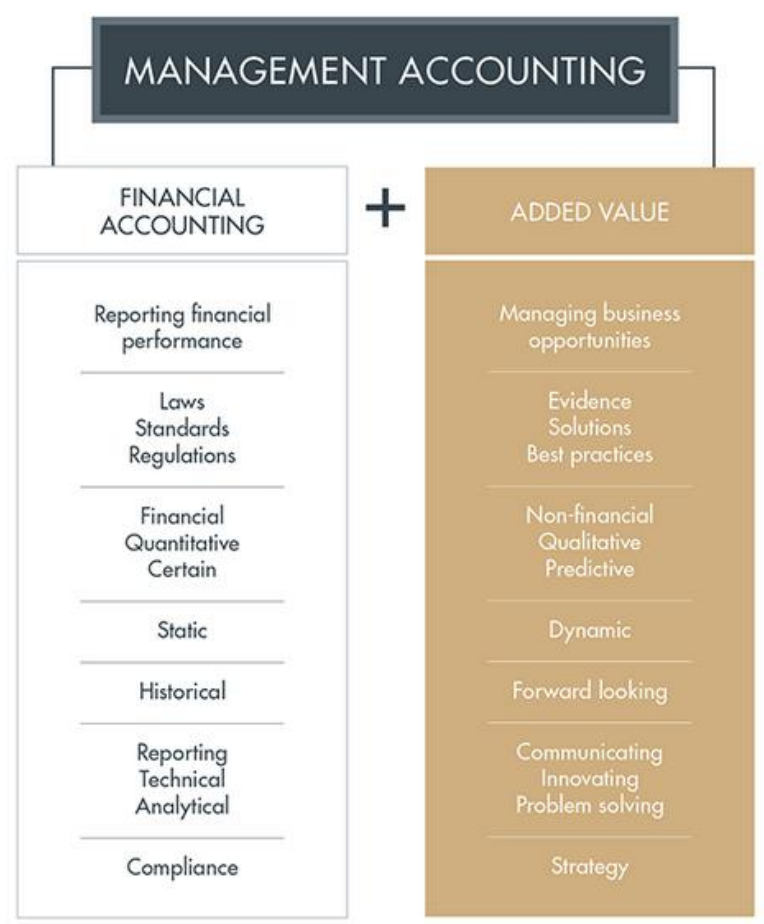

Figure 1. The Architecture of the Enterprise Management Accounting

In this paper, we conduct research on the modern enterprise management accounting development trend and the influences on promoting the enterprise. At present, the application of the management accounting in enterprise management in our country is at a critical turning point, the application in the enterprise urgent need to past experience to summarize and improve, form our country management accounting theory and method system, to meet the needs of the enterprise management mechanism change to ensure the high efficiency of enterprise production and the operation, and to improve the adaptability of the enterprise itself. In the later parts, we will discuss in detail.

\section{Our Proposed Methodology and Perspective}

The Accounting Development Trend. Along with the development of the economy, the change of the enterprise financial environment, the goal of financial accounting is gradually from the concept of the fiduciary duty decision-making 
useful concept, to provide information to corporate stakeholders decision became the primary goal of the financial and basic accounting reports in view of the various stakeholders to focus on different aspects of information and the information required to much more and more, in addition to provide financial information of financial and accounting reports, but also provide non-financial information; At the same time as the quantity of information, in order to better find information related to decision-making, financial and accounting reports should be to provide the multi-level information development [4-5].

As the international economic globalization, international communication is becoming more and more widely, multinational companies continue to grow stronger, accounting business transactions "as a common language, have crossed the border, and to reflect international economic activities, to provide information in a broader space and time. Due to differences in countries accounting deals with multinational company requirements, under the joint action of as also inevitable requirement to produce a corresponding model of accounting. Our country at present has become attract the foreign direct investment in the most countries in the world is also more and more abroad, China's enterprises to overseas issuance of stocks or bonds, merger and acquisition, investment in factories and so on, so not only is economic globalization requires a globally accepted accounting standards, development of China's economy is actually need a globally accepted accounting standards for easy operation, as the international accounting coordination and convergence in China's interest, too.

The Enterprise Management Accounting. With the development of the market economy in our country, management accounting is becoming more and more important as the development of capital market need specification is given priority to with external reports of financial accounting, but the prosperity of the capital market need more advanced management accounting mainly on the internal management. Difficulties and prospects for the reform of state-owned enterprise from one side show the huge space of the development of the management accounting in our country.

Management accounting's main function is to improve the core enterprise economic efficiency and benefits of various accounting control system, preparation of provide enterprise internal management accounting need a variety of data, information, etc. In other words, management accounting is to use the appropriate concepts and techniques to handle with business history of individual or predictive economic data, to predict the economic outlook, participation in economic decision-making, planning and business objectives, control the economic process, purpose of business performance assessment. At present, the application of management accounting in enterprise management in our country is at a critical turning point, the urgent need to past experience to summarize and improve, form a theory and method of management accounting system with Chinese characteristics [6].

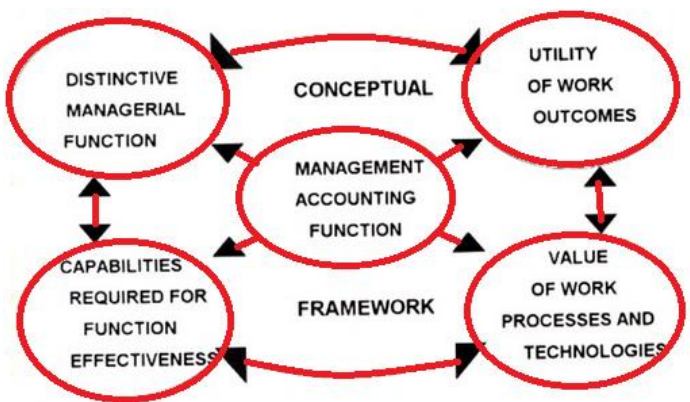

Figure 2. The Inner Components of the Enterprise Management Accounting

The development of social economy and the behavior theory, system theory, decision theory and the economic theory of the development of management accounting theory provides the background and the basis. Management accounting at the same time of strengthening control, began to perform the function prediction, 
decision-making, and gradually formed is given priority to with primary forecast, decision-making, and adapted to the modern requirements of the accounting information management system, meet the managers in an increasingly complex and diverse organizational environment as the need for information and control. The suggestions for enhancing the management accounting could be summarized as the follows. (1) Management accounting must strengthen the typical case study and go the way of theory and the practice closely integrated. Ensure the production and operation of an enterprise run efficiently, improve the adaptability of the enterprise itself, eventually is conducive to the further development of management accounting application. (2) Set up specialized management accounting management institutions, to promote the practical application of the theory. Through the role of management accountants professional organization of basic western developed countries and operating results, our country also is necessary according to the actual situation of domestic advanced experience of western to form their own institute of management accountants in our country, promote the professionalization of management accounting. (3) To further strengthen management accounting education and improve accounting personnel quality. Under the condition of knowledge economy, the composition of enterprise staff with high intelligence staff as the main body that greatly extended functions of the management accounting, management accounting personnel should possess higher comprehensive qualities and corresponding features [7].

The Enterprise Development and Management Paradigm. Smaller companies are not equal to is not important. At any time, any country, should be medium enterprises coordinate with each other, mutual cooperation, common development, and the enterprise scale as the greater the number of the less. Therefore, medium enterprises constitute pagoda shape, in number that a few large enterprises in the top of the pagoda, many small businesses become the base of the pagoda. Practice has proved that have no direct relationship with the enterprise scale economic benefit. But in the past a long time, the theoretical knowledge will equate enterprise scale and the economic efficiency, think the enterprise scale is bigger, the better the economic benefits. This kind of ideological understanding always can be traced back to the classical economic theory reflected from the figure three [8-9].

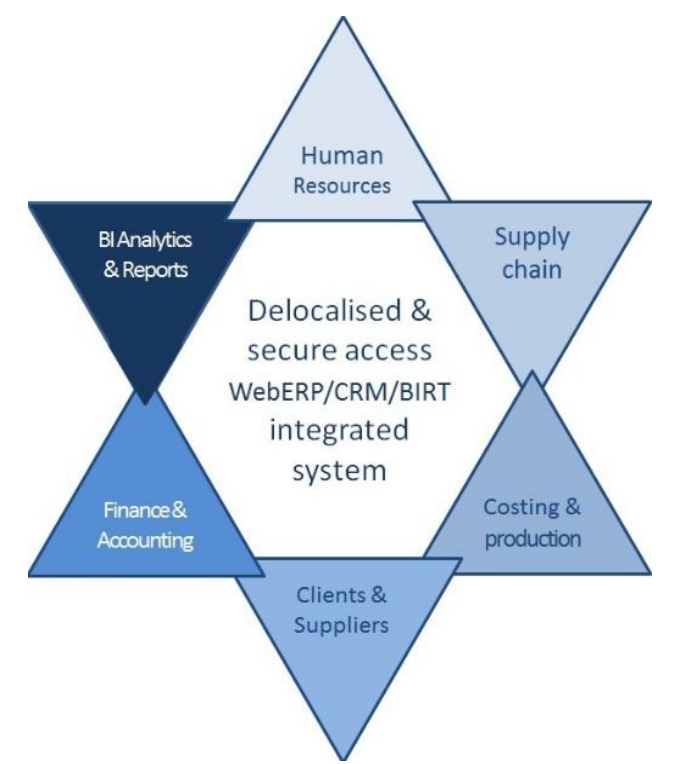

Figure 3. The Enterprise Management and Development Principles

Enterprise management is one of the most essential problem is how to arouse the enthusiasm of the people, and give full play to the potential of people, in order to realize the goals of the organization. Knowledge management is a kind of based on knowledge, people-oriented humanized management. It through effective method to recognize the benefits of people, the fault of the inhibition, provide can exert the potential of people, intelligence and creative environment, use the knowledge people have to create the wealth. Enterprises to implement knowledge management is through the basic 
purpose of knowledge management to improve enterprise management environment of strain ability, innovation ability, decision-making ability fundamentally cultivate and promote enterprise core competitiveness, with the role of specific performance for following two aspects. (1) Help to improve the adaptability of enterprises knowledge management. The quickening pace of economic globalization, enterprise in order to keep stabilize your own position, and not to be knocked out prematurely, and require companies can make a quick response to changes in the market, has the stronger ability to cope with situation, knowledge management, through the accumulation, storage and application of knowledge, can help enterprises rapidly changing the business signal perception, weak market information, and according to the requirements of resource organization, rapid and effective response to emergencies, knowledge management to improve the quality of the member companies and skills, to a large extent can strengthen the of information and market the most the right judgment, improve the strain capacity of enterprise, to maintain and promote enterprise's core competitiveness. (2) Knowledge management to improve the enterprise innovation ability. Enterprises through knowledge management activities, to encourage and the foster new ideas, new idea, new knowledge, maximize the enterprise employees attracted to come up with new ideas and the ability of cooperation, the common development of new products and services, so as to improve the innovation ability of enterprises.

The Enterprise Finance. In the process of reproduction of the enterprise, the cycle, the cycle of the capital movement is the financial activities of an enterprise. In general, the enterprise's financial activities can be divided into the four aspects, namely enterprise financing caused by the financial activities, financial activities caused by business investment, as caused the financial activities of the enterprises and enterprise distribution of the financial activities. Accordingly, the enterprise financial management also includes enterprise financing management, investment management, management of working capital management and profits and its distribution.

The primary task of enterprise financial management is to establish and perfect the basic financial management system to improve the company's internal financial control mechanism. In the financial management as the main means of value-added, financial situation is a matter of every enterprise is the lifeblood of the survival of the growing, financial technology today, and every enterprise concern from all walks of life to our financial professional under the concept of the continuous innovation, to review all aspects of the financial management, especially should pay attention to the function of the financial internal control and its status in the entire financial management system.

\section{Conclusion}

In this paper, we conduct research on modern enterprise management accounting development trend and the influences on promoting the enterprise. In management accounting strategy implementation, the need to provide concrete implementation process, the comprehensive budget cannot efficiently, help of balanced scorecard and homework cost method. Using the method of quantitative analysis, combined with the company's mission and vision, to enterprise's internal and external environment as well as the various aspects of the competitor analysis, thus forming a strategic mode suitable for enterprise actual situation from the enterprise's strategic formation conditions, the formation stage of the strategic needs of enterprise resource and the core competitiveness of related qualitative and the quantitative analysis. Under this background, this paper proposes the novel paradigm for enterprise management accounting which holds special significance. 


\section{References}

[1] Fullerton, Rosemary R., Frances A. Kennedy, and Sally K. Widener. "Lean manufacturing and firm performance: The incremental contribution of lean management accounting practices." Journal of Operations Management 32.7 (2014): 414-428.

[2] Cullen, John, et al. "Reverse logistics in the UK retail sector: A case study of the role of management accounting in driving organisational change." Management Accounting Research 24.3 (2013): 212-227.

[3] Herbert, Ian P., and Will B. Seal. "Shared services as a new organisational form: Some implications for management accounting." The British Accounting Review 44.2 (2012): 83-97.

[4] Cohen, Sandra, and Sotiris Karatzimas. "Has IFRS adoption affected management accounting systems? Empirical evidence from Greece." International Journal of Accounting, Auditing and Performance Evaluation 9.3 (2013): 268-285.

[5] Seal, Will. "Some proposals for impactful management control research." Qualitative Research in Accounting \& Management 9.3 (2012): 228-244.

[6] Fadzil, Faudziah Hanim Bt, and Abdelqader Rababah. "Management accounting change: ABC adoption and implementation." Journal of Accounting and Auditing: Research \& Practice 2012 (2012): 1-17.

[7] Young, S. Mark, et al. "It's All About All of Us-The Rise of Narcissism and Its Implications for Management Control System Research." Journal of Management Accounting Research (2015). 